\title{
The subcutaneous ventricular reservoir: an effective treatment for posthemorrhagic hydrocephalus
}

\author{
Sarah J. Gaskill ${ }^{1}$, Arthur E. Marlin ${ }^{1,2,3}$, and Susan Rivera ${ }^{4}$ \\ 1 University of Texas Health Science Center at San Antonio, 7703 Floyd Curl Drive, San Antonio, TX 78284, USA \\ 2 Department of Pediatrics, ${ }^{3}$ Department of Surgery (Neurosurgery), and ${ }^{4}$ NICU, Santa Rosa Children's Hospital, \\ 519 West Houston Street, San Antonio, TX 78205, USA
}

\begin{abstract}
Use of the subcutaneous ventricular reservoir in the treatment of posthemorrhagic hydrocephalus was studied in a series of 38 patients. All of the patients were considered to be medically labile. Additionally, all had failed conservative modes of therapy consisting of lumbar punctures with or without furosemide or acetazolamide. Management of the hydrocephalus consisted of reservoir placement. Subsequently, taps were performed at various intervals and amounts, depending upon the degree of ventricular dilatation as determined by sonography and signs of increased intracranial pressure. The majority of reservoirs were left in place for 1-2 months. There were no reservoir infections. Once the patients were medically stable, the reservoir was removed and a shunt placed. Eight patients died before shunt placement and 2 patients died after shunting, reflecting a $29 \%$ mortality. In no case was a death related to the shunt, but rather reflected the medical lability of the patient population. Four patients (15\% of surviving patients) did not require shunting. The total shunt infection rate was $6.9 \%$ (among survivors with a shunt in place, $7.7 \%$ ). These results support the use of the reservoir as an easy and effective means of protecting the cortical mantle while decreasing morbidity related to future shunt placement.
\end{abstract}

Key words: Posthemorrhagic hydrocephalus - Intraventricular hemorrhage - Ventricular reservoir - Hydrocephalus.

Posthemorrhagic hydrocephalus in the preterm infant has become very common in neonatal practice. In the United States, 35,000 infants less than $1,500 \mathrm{~g}$ are born yearly; $35 \%-45 \%$ of these will have germinal matrix hemorrhages. A significant number $(20 \%-50 \%)$ of these will go on to develop posthemorrhagic ventriculomegaly [16]. This ventriculomegaly may be temporary or progressive. Usually these infants have multiple medical problems. They can be

Offprint requests to: A. E. Marlin, Pediatric Neurosurgery, Rosa Verde Towers Suite 1001, 343 West Houston Street, San Antonio, TX 78205, USA quite unstable and at significant risk with any therapeutic maneuver. Therefore, we have treated these very ill premature infants with a subcutaneous ventricular reservoir. This technique has been limited thus far to premature infants with multiple medical problems in whom lumbar puncture and other conservative means to control increased intracranial pressure or progressive ventriculomegaly and head growth have failed. The results of a series of 38 patients are presented.

\section{Case material}

All patients in this series had severe respiratory distress syndrome or bronchopulmonary dysplasia and other common problems of prematurity. They were all considered medically labile. All failed conservative therapy consisting of lumbar punctures or lumbar punctures and furosemide or acetazolamide. Lumbar punctures were considered a failure in two instances: when they were unable to retard ventriculomegaly as determined by sonography and clinical signs of increased intracranial pressure, or when they were no longer technically feasible. The infants were between 27 and 33 weeks' gestation and $650-1,850 \mathrm{~g}$ (Fig. 1). The age at which the reservoir was placed was most commonly between the 3 rd and 4 th weeks of life but varied from the 1st week to the 2nd month (Table 1). All children, by definition, had a grade 3 or 4 hemorrhage according to the classification of Papile [12]. The reservoir used was a 3-cm cerebral catheter reservoir - LeRoy design (Codman and Shurtleff, Inc., Randolph, Mass.). The reservoir was placed with the child under local anesthesia in the intensive care unit. The reservoir was then aspirated daily with a 27 -gauge butterfly needle. Initially $10 \mathrm{cc}$ of CSF was removed. After 3-5 days, repeat sonography was performed to assess ventricular size. The amount and frequency of CSF aspiration were then changed empirically to maintain the ventricular system in a mildly dilated state, as determined by serial sonograms. The frequency of sonograms varied with the age of the infant, the length of time the reservoir was in place, and the degree and fluctuation of ventriculomegaly. Sonograms were initially more frequent if the ventriculomegaly did not respond readily. Once stabilized, sonograms were performed weekly. The amount of CSF aspirated varied from 5 to $10 \mathrm{cc}$ every other day to $15 \mathrm{cc}$ three times daily.

\section{Surgical technique}

The patient was kept in the neonatal intensive care unit in the infant warmer on the ventilator without any changes in ventilator 


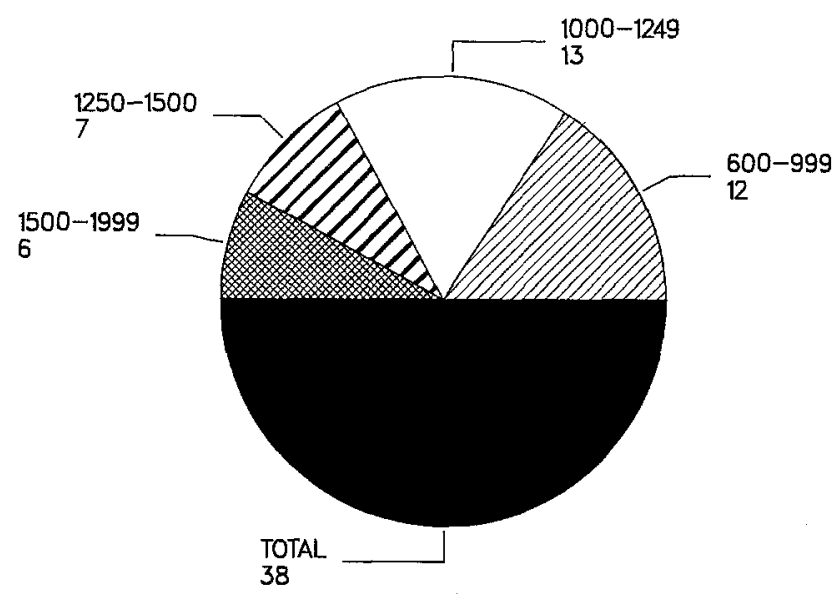

Fig. 1. Gestational weight in grams

Table 1. Age at reservoir placement

\begin{tabular}{lllllll}
\hline $\begin{array}{l}\text { Gestational weight } \\
\text { in }\end{array}$ & $\begin{array}{l}1-7 \\
\text { Days }\end{array}$ & $\begin{array}{l}8-14 \\
\text { Days }\end{array}$ & $\begin{array}{l}15-21 \\
\text { Days }\end{array}$ & $\begin{array}{l}22-29 \\
\text { Days }\end{array}$ & $\begin{array}{l}30-45 \\
\text { Days }\end{array}$ & $\begin{array}{l}\text { Days } \\
\text { Das }\end{array}$ \\
\hline $600-999$ & 0 & 1 & 3 & 5 & 2 & 1 \\
$1000-1249$ & 1 & 4 & 4 & 2 & 2 & 0 \\
$1250-1499$ & 1 & 0 & 3 & 2 & 1 & 0 \\
$1500-1999$ & 0 & 1 & 2 & 3 & 0 & 0 \\
Total & 2 & 6 & 12 & 12 & 5 & 1 \\
\hline
\end{tabular}

Table 2. Duration of reservoir. +, Death before shunt; $R$, removed before shunt; $0,1 \mathrm{pt}$ lost to follow-up

\begin{tabular}{lllllll}
\hline $\begin{array}{l}\text { Gestational } \\
\text { weight in }\end{array}$ & $\begin{array}{l}0-14 \\
\text { Days }\end{array}$ & $\begin{array}{l}15-30 \\
\text { Days }\end{array}$ & $\begin{array}{l}31-60 \\
\text { Days }\end{array}$ & $\begin{array}{l}61-90 \\
\text { Days }\end{array}$ & $\begin{array}{l}91-120 \\
\text { Days }\end{array}$ & $\begin{array}{l}>120 \\
\text { Days }\end{array}$ \\
\hline $600-999$ & 0 & $2^{1+}$ & 5 & 4 & 1 & 0 \\
$1000-1249^{0}$ & 0 & $4^{1+}$ & $5^{1+}$ & 1 & 0 & $2^{\mathrm{R}}$ \\
$1250-1499$ & $1^{+}$ & $4^{1+}$ & 1 & 1 & 0 & 0 \\
$1500-1999$ & 0 & $4^{1+}$ & 0 & 0 & 0 & $2^{\mathrm{R}}$ \\
Total & $1^{1+}$ & $1^{4+}$ & $11^{1+}$ & 6 & 1 & 4 \\
\hline
\end{tabular}

settings or monitoring. If not already on an antistaphylococcal agent, an antibiotic (nafcillin until 1984 and thereafter vancomycin) was begun. This was usually continued for $48 \mathrm{~h}$. The head was positioned laterally or in a straight supine position. The right side foccasionally the left if the left ventricle was considerably larger than the right or the right filled with clot) was shaved in the frontal and parietal regions to the midline. The skin was prepared with a provoiodine solution. Using a small-gauge needle, the skin anterior to the coronal suture and over the parietal bone was infiltrated with normal saline. A semilunar incision approximately $2.5 \mathrm{~cm}$ in length was then made anterior to the coronal suture. The skin was retracted posteriorly to expose the coronal suture, which was incised. The reservoir, using its stylet, was then placed in the right lateral ventricle. The end of the reservoir was closed with the metal plug secured with a 3-0 silk tie. The dome of the reservoir was seated over the parietal bone and aspirated to assure good flow. The skin was closed with 4-0 prolene suture. Provoiodine ointment and an occlusive dressing were applied.

\section{Results}

The duration the reservoir was left in place is shown in Table 2. Most reservoirs are needed for 1 to 2 months. Eight patients died before a shunt was placed (Fig. 2). Three patients died after shunting, reflecting a $29 \%$ mortality. In no case was the death related to the shunt; rather, the high mortality reflects the seriousness of associated medical problems.

Of particular note is that in the group of 29 survivors with reservoirs in place (one patient was transferred to another hospital with a reservoir in place and subsequently shunted and lost to further follow-up), there were no reservoir infections despite innumerable aspirations. Even with subsequent shunting in those patients requiring shunts, the infection rate was remarkably low with no shunt infections diagnosed prior to discharge, two infections diagnosed when followed out to 3 months after discharge, and no subsequent infections when carried out to 6 months after discharge. This represents a total shunt

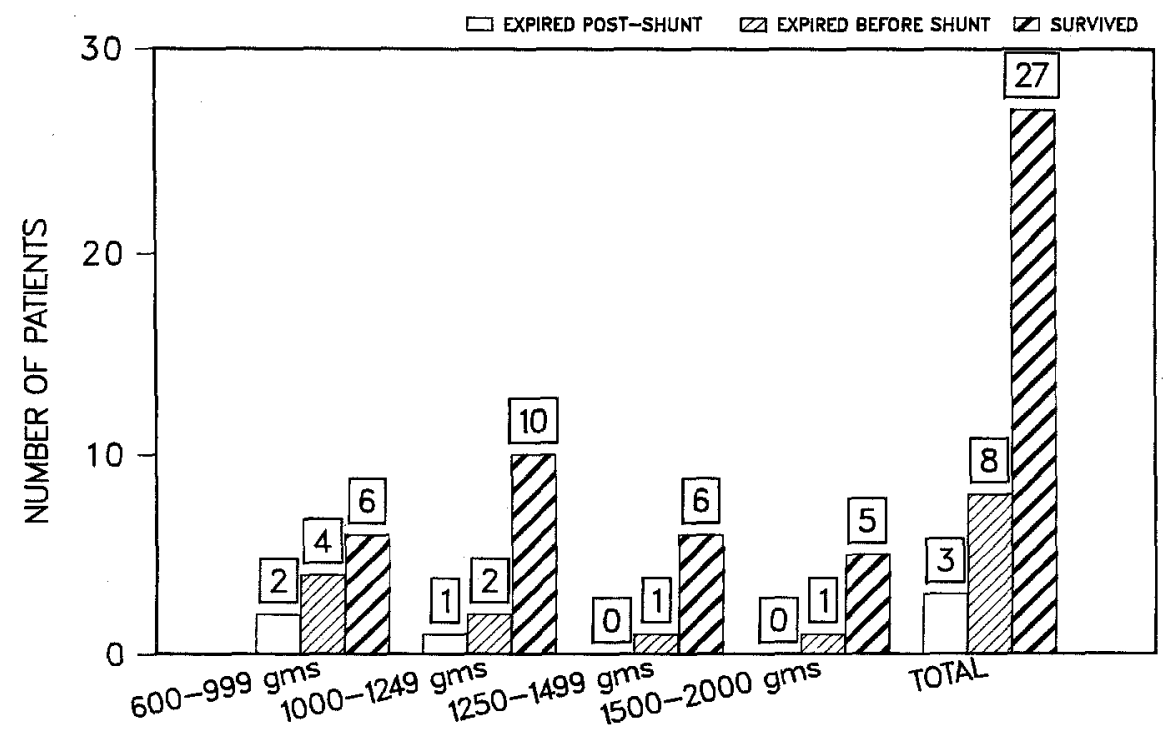

Fig. 2. Survival rates 


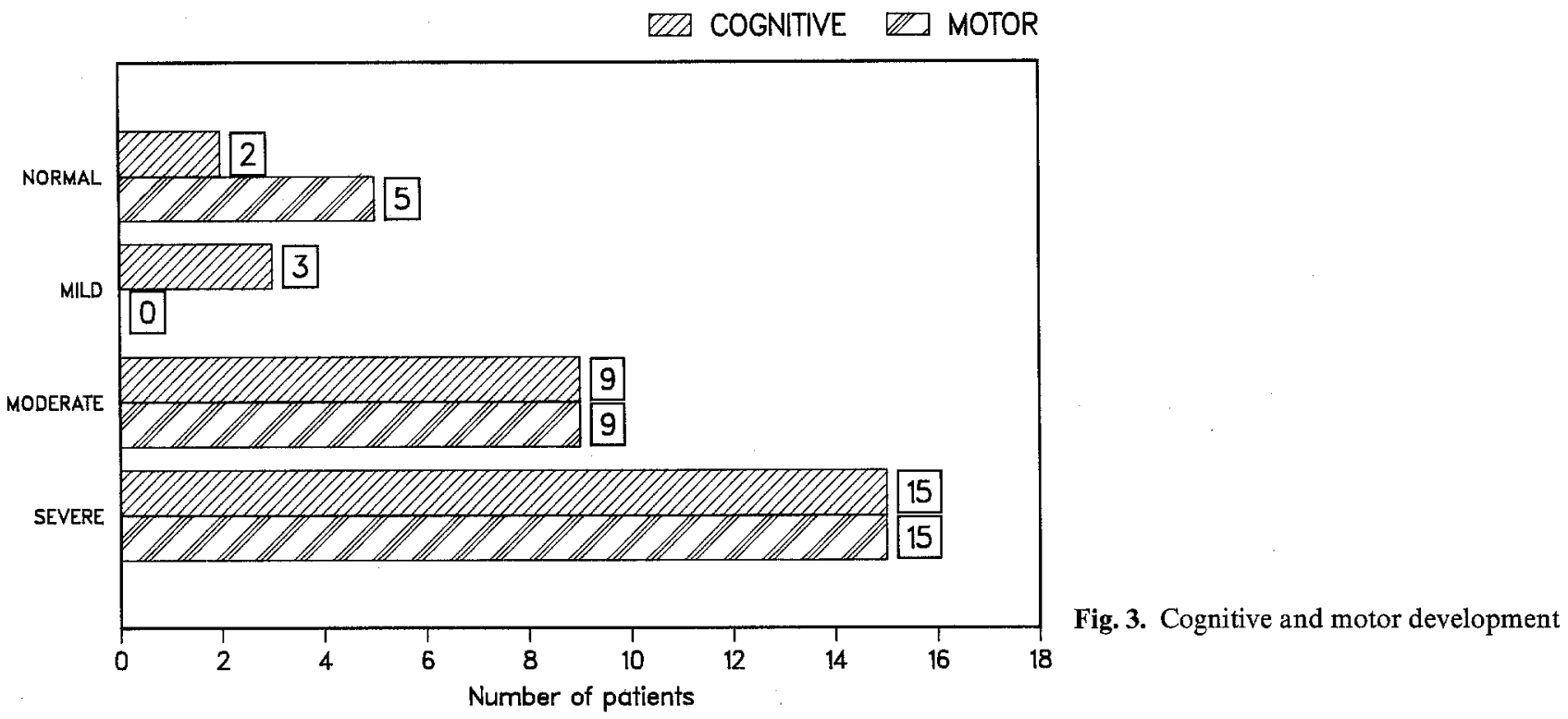

Table 3. Shunt revisions. 4 patients expired; 1 patient lost before $\mathrm{d} / \mathrm{c} ; 5$ patients lost to late $\mathrm{f} / \mathrm{u}$.

\begin{tabular}{lrlll}
\hline $\begin{array}{l}\text { Gestational weight in } \\
G\end{array}$ & $N$ & $\begin{array}{l}\text { Before } \\
\text { discharge }\end{array}$ & $\begin{array}{l}\text { Within } \\
3 \text { months } \\
\text { of DC }\end{array}$ & $\begin{array}{l}\text { Within } \\
6 \text { months } \\
\text { of DC }\end{array}$ \\
\hline $600-999$ & 8 & 3 & 0 & 2 \\
$1000-1249$ & 11 & 0 & $3^{\mathrm{b}}$ & 1 \\
$1250-1499$ & 6 & $1^{\mathrm{a}}$ & 3 & $2^{\mathrm{a}}$ \\
$1500-1999$ & 5 & 0 & 0 & 0 \\
Total & 30 & 4 & 6 & 5 \\
\hline
\end{tabular}

a 1 patient with multiple revisions

b Patients with multiple revisions

infection rate of $6.9 \%$. Removing from consideration the three patients who died subsequent to shunting, this reflects a shunt infection rate of $7.7 \%$.

Four patients did not require shunts. This is $10.5 \%$ of the total patients, $14 \%$ of those surviving long enough for shunts, and $15 \%$ of the total survivors. These patients were weaned from their taps with nonprogressive mild-tomoderate ventricular dilatation and without signs of increased intracranial pressure.

A total of 30 patients required shunts $(29$ shunted within our institution, and 1 shunted at another hospital). Four (13.8\%) required revision before discharge (Table 3 ). Three of the 4 were in the group under $1 \mathrm{~kg}$; one went on to require multiple revisions. There were 6 more patients that had revisions within the 3 months after discharge. Thus, within 3 months after discharge a total of 10 patients $(34.5 \%)$ required revisions. One was a predischarge revision patient and 2 others required three revisions. Five patients were lost to late follow-up (after 6 months).

Developmental assessment, as shown in Fig. 3, is only a gross assessment at follow-up examinations. It is not presented as neurodevelopmental data, but as a general impression of outcome in these children. Approximately half have very severe retardation and motor deficits, making them totally dependent on a caretaker. About 17\% of the 29 survivors seen in follow-up had a favorable outcome with either normal cognitive and motor development or only minimal deficits.

\section{Discussion}

Treatment of the preterm infant with progressive posthemorrhagic ventriculomegaly is a major problem for the neonatologist and neurosurgeon. The initial therapeutic maneuver of serial lumbar punctures is most frequently utilized for management of ventriculomegaly. There have been conflicting reports in the literature regarding the efficacy of this treatment modality. Papile reports that in 11 of 12 infants with evolving ventriculomegaly serial lumbar punctures resulted in an arrest of the progression of hydrocephalus [13]. However, Montovani found that serial lumbar punctures on 19 infants with "severe" CT scans was not effective in either arresting ventriculomegaly or reducing the mortality [8]. More recently, Kreusser et al. concluded that lumbar punctures were effective in ameliorating progressive hydrocephalus on a temporary basis if there was a communicating hydrocephalus present and an adequate amount of CSF was aspirated [7]. As this conflict in the literature demonstrates, ventriculomegaly may progress despite lumbar puncture therapy. In other cases lumbar punctures become technically impossible. A dilemma then evolves because of the infant's condition and the inability to withdraw adequate CSF to control increased intracranial pressure. There are only a few management options available in the low-weight, critically ill infant. It is clearly reasonable to make every effort to protect the cortical mantle and normalize intracranial pressure to optimize outcome. This has been recently confirmed in the literature by Etches et al. [2]. They 
reviewed the histories of 29 infants with low birth weight (less than $2,000 \mathrm{~g}$ ) who had been shunted "for posthemorrhagic hydrocephalus. Their data indicated that the neurodevelopmental outcome was directly associated with the interval between the diagnosis of hydrocephalus and the time of shunting. Those infants who had the largest delay in treatment had the worst outcome. Thus, waiting for the child to overcome the problems of prematurity while letting the hydrocephalus advance is clearly not a satisfactory treatment alternative.

Serial ventricular punctures is another treatment option. The risks with multiple punctures are intracranialparenchymal, ventricular, or subdural hemorrhage. With multiple taps and increased intracranial pressure, subsequent porencephalies may result. Infection is probably a very unusual complication, as it is with lumbar punctures. The major disadvantage is that multiple punctures are required. This then cannot be recommended as an effective long-term alternative.

External ventricular drainage (EVD) could be established with a single ventricular puncture. The Hanover series of 38 patients is fairly comparable to the present study [14]. The duration of drainage was considerably less, averaging 21 days with a mean of 1.8 drains per patient. Ten patients died. The complications of placement were apnea (10\%), hemorrhage (8\%), and infections (6\%). The drains were removed or changed because of occlusion or suspected infection; $13 \%$ became dislodged; $11 \%$ were thought to be infected. EVD thus becomes an acceptable option if the duration is short. The complication rate, however, is still considerably higher than with the use of the subcutaneous ventricular reservoir, where there were no infections in 38 patients. With ventricular reservoirs there were no occlusions, dislodgements, or associated hemorrhages. The infants were on ventilators at the time of placement; thus apnea was not a problem.

Early shunting is the option chosen by the San Diego group reported by James et al. and Boynton et al. [1, 5]. Here the infection rate was $26.9 \%$ if followed to discharge, $35.7 \%$ within 6 weeks and 50\% within 3 months; $26.4 \%$ required revision during the nursery stay and there were 142 revisions (1-11 per patient) in 34 patients within 3 months. The infection and revision rate here are obviously too high. With the initial use of a subcutaneous ventricular reservoir before shunting in our group, there were no infections during the nursery stay. When followed out to 6 months after discharge, the shunt infection rate was $7.7 \%$ (one patient had multiple revisions); $13.8 \%$ of the patients required shunt revision during the nursery stay. Following these to 3 months postdischarge, a total of 10 patients (34.5\%) needed revisions. At 6 months postdischarge 15 patients $(51 \%)$ required revision. The reservoir thus decreases the morbidity associated with early shunting. This point is confirmed by Frerebeau et al. [3] who concluded in their study of 39 cases of nontumoral hydrocephalus that there is significant risk associated with early operations in infants with low birth weights. They therefore recommend the utilization of transitory palliative treat- ment for optimal outcome. The reservoir is demonstrated by the present study to serve this temporizing function nicely.

The use of the subcutaneous ventricular reservoir is simple, safe, and effective. There were no harmful effects of placement. The lack of infection in the series of 38 reservoir placements is of particular importance as ventriculitis is clearly correlated with a diminished I.Q. in children with meningomyelocele and hydrocephalus [11]. It seems reasonable to extrapolate these findings to the current population, as other authors have found that children with communicating hydrocephalus and meningomyelocele (without a history of central nervous system infections) were not intellectually impaired [10]. Therefore, we are left with the supposition that it is the infectious process resulting in a destruction of nervous tissue which causes the intellectual decline, rather than the dynamics of hydrocephalus per se.

While intracranial pressures were not measured in the current study, Kaiser and Whitelaw have demonstrated that there is a positive correlation between increases in ventricular size and CSF pressure in posthemorrhagic ventriculomegaly [6]. Judging by the clinical assessment of the fontanelle, suture separation and ventricular size on sonography, the reservoir is effective in reducing ventricular size. thereby reducing intracranial pressure and promoting protection of the cortical mantle. The frequency and amount of aspiration is empirically determined by the amount to obtain these goals. If the fontanelle bulged or the sutures separated between taps, the frequency was increased. If ventricular size was not reduced, amounts (up to $15 \mathrm{cc}$ ) and frequency (up to 3 times daily) were increased to accomplish this. The average amount and frequency were $10 \mathrm{cc}$ twice daily.

Four patients in the series did not require shunting. Thus, placement of the reservoir did not necessarily obligate the patient to a shunt. The infants could be shunted with decreased morbidity once they were independent of the respirator and the major life-threatening problems of their prematurity were resolved. The question then arises regarding the difference in neurodevelopmental outcome between these two groups. Follow-up on those patients who did not require shunts in this series is not available. However, Sasidharan et al. [15] addressed the issue of neurodevelopmental outcome in shunted versus nonshunted patients. They followed 36 infants with grade III and IV intraventricular hemorrhages to compare the developmental quotient (DQ) of those who required shunting versus those who remained nonshunted. They found that those infants who required shunting had a poorer neurodevelopmental outcome than those who did not require shunts. These results, while interesting, are not conclusive about the role of ventriculomegaly in neurodevelopment. It is probable that those infants who go on to require shunting have sustained a more significant and deleterious bleed (thereby explaning the lower DQ). These data support the necessity for maximal protection of nervous tissue. By maintaining a reasonable ventricular 
size with a reservoir or other treatment alternative, neurodevelopmental outcome is optimized.

The reservoir has been a logical and benign solution to a most difficult problem. This has created trends in our neonatal unit. With the establishment of minimal stimulation protocols and the difficulty of lumbar punctures in these infants, our neonatologists frequently request early reservoir placement. A series of earlier placements is currently being established. One would expect even better results because many of these patients will be those with only transitory ventricular dilatation. Another trend is towards later shunting. The larger and more mature the child, the less the morbidity and the better the shunt function. The normal intracranial pressure in a preterm infant is probably atmospheric or less. A shunt remains a pressure apparatus even when a very low pressure system is used. The small amount of pressure generated by the readily expandable skull and the increased intrathoracic and intraabdominal pressures caused by the respirator may theoretically inhibit shunt function. As the child grows, the skull thickens and becomes less. expansile. Respirator support is no longer necessary and CSF protein is reduced. The shunt, therefore, functions more efficiently. As the reservoir is effective in protecting the cortical mantle, we tend to shunt just prior to discharge from the nursery, when conditions are optimal for shunt function. A further study is needed to see if this will further decrease revisions and infections.

\section{References}

1. Boynton BR, Boynton CA, Merritt TA, Vaucher YE, James HE, Bejar RF (1986) Ventriculoperitoneal shunts in low birth weight infants with intracranial hemorrhage: neuro-developmental outcome. Neurosurgery 18: 141-145

2. Etches PC, Chir B, Ward TF, Bhui PS, Peters KL, Robertson CM (1987) Outcome of shunted posthemorrhagic hydrocephalus in premature infants. Pediatr Neurol 3:136-140

3. Frerebeau P, Guillen M, Privat JM, Benezech J (1982) Nontumoral Hydrocephalus in newborns. Monogr Neural Sci 8: 209-212

4. James HE, Bejar R, Gluck L, Coen R, Merritt A, Mannino F, Bromberger P, Sunders B, Schneider H (1984) Ventriculoperitoneal shunts in high-risk newborns weighing under 2,000 grams: a clinical report. Neurosurgery 15:198-202
5. James HE, Bejar R, Merritt A, Gluck L, Coen R, Mannino F (1984) Management of hydrocephalus secondary to intracranial hemorrhage in the high-risk newborn. Neurosurgery $14: 612-617$

6. Kasiser AM, Whitelaw GL (1985) Cerebrospinal fluid pressure during post haemorrhagic ventricular dilatation in newborn infants. Arch Dis Child 60:920-924

7. Kreusser KL, Tarby TJ, Kovnar E, Taylor DA, Hill A, Volpe JJ (1985) Serial lumbar punctures for at least temporary amelioration of neonatal posthemorrhagic hydrocephalus. Pediatrics 75:719-724

8. Mantovani JF, Pasternak JF, Oommen MP, Allan WC, Mills MT, Casper J, Volpe JJ (1980) Failure of daily lumbar punctures to prevent the development of hydrocephalus following intraventricular hemorrhage. J Pediatrics 97:278281

9. Marlin AE (1980) Protection of the cortical mantle in premature infants with posthemorrhagic hydrocephalus. Neurosurgery 7:464-468

10. McCullough DC, Balzer-Martin LA (1982) Current prognosis in overt neonatal hydrocephalus. J Neurosurg 57:378-382

11. McLone DG, Czyzewski D, Raimondi AJ, Sommers RC (1982) Central nervous system infections as a limiting factor in the intelligence of children with meningomyelocele. Pediatrics 70:335-342

12. Papile LA, Burstein J, Burstein R, Koffler H (1978) Incidence and evolution of subependymal and intraventricular hemorrhage: a study of infants with birth weights less than 1,500 grams. J Pediatrics 92:529-534

13. Papile L, Burstein J, Burstein R, Koffler H, Koops B, Johnson J (1980) Posthemorrhagic hydrocephalus in low-birth-weight infants: treatment by serial lumbar punctures. J Pediatr 97: 273-277

14. Rhodes T, Edwards WH, Harbaugh RE, Saunders RS, Scott M (1986) External ventricular drainage for initial treatment of neonatal posthemorrhagic hydrocephalus. Presented at the Pediatric Section of AANS, Pittsburg

15. Sasidharan P, Marquez E, Dizon E, Sridhar CV (1986) Developmental outcome of infants with severe intracranialintraventricular hemorrhage and hydrocephalus with and without ventriculoperitoneal shunt. Child's Nerv Syst 2: $149-152$

16. Volpe J (1987) In: Volpe JJ (ed) Neurology of the newborn. Intracranial hemorrhage, periventricular-intraventricular hemorrhage of the premature infant. Saunders, Philadelphia

Received August 3, 1987; in revised form March 15, 1988 